\title{
Quercetina protege contra dano oxidativo causado por paraquat em fígado e rim de ratos
}

\section{Quercetine protects against oxidative damage caused by paraquat in liver and kidney of rats}

Quercetina protege contra daño oxidativo causado por paraquat en hígado y riñón de ratos

\author{
Tatiane Julia Hahn ${ }^{1}$ \\ Josiane Woutheres Bortolotto ${ }^{2}$ \\ Thiago de Souza Claudino ${ }^{3}$ \\ Gabriela Bonfanti-Azzolin ${ }^{4}$
}

${ }^{1}$ Farmacêutica, egressa do Curso de Farmácia, Universidade de Cruz Alta. E-mail: juliadisner@hotmail.com, Orcid: http://orcid.org/0000-0003-2721-6701

2 Doutora, docente do Curso de Farmácia, Universidade de Cruz Alta. E-mail: bortolotto@unicruz.edu.br, Orcid: http://orcid.org/0000-0003-0271-1685

${ }^{3}$ Doutor, docente do Curso de Farmácia, Centro Universitário Metodista IPA, E-mail: thiago.claudino@ipa.metodista.br, Orcid: http://orcid.org/0000-0003-1845-4935

${ }^{4}$ Doutora, docente do Programa de Pós-Graduação Stricto Sensu em Atenção Integral à Saúde, Universidade de Cruz Alta. E-mail: gbonfanti@unicruz.edu.br, Orcid: http://orcid.org/0000-0003-2602-6092 
Resumo: As intoxicações por paraquat (Pq) são frequentes no país e seu mecanismo de ação tóxica envolve a geração de estresse oxidativo, que pode ser combatida com antioxidantes exógenos como a quercetina (Q). Assim, ao avaliar o papel desse flavonoide em dano causado por Pq em modelo experimental animal, in vitro, observou-se uma redução no nível de lipoperoxidação hepático, sugerindo maior sensibilidade desse tecido do que o renal. Também, quando em associação, $P q+Q$ foram capazes de provocar a inibição da enzima $\delta$-aminolevulinato desidratase ( $\delta$-ALA-D), possivelmente por mecanismo de quelação, não relacionado aos grupos sulfidrílicos da enzima. In silico, a $Q$ apresentou boa absorção intestinal, alta taxa de ligação às proteínas plasmáticas, potencial mutagênico, carcinogênico e inibitório sobre enzimas do metabolismo. Assim, acredita-se que a dieta alimentar rica em $Q$ ou sua suplementação pode trazer benefícios à saúde da população, especialmente àqueles expostos a herbicidas, como o Pq.

Palavras-chave: estresse oxidativo; in silico; agrotóxicos; antioxidante.

\begin{abstract}
Abstrat: Paraquat (Pq) intoxications are frequent in the country and its toxic mechanism of action involves the generation of oxidative stress, which can be combated with exogenous antioxidants such as quercetin ( $\mathrm{Q}$ ). Thus, when assessing the role of this flavonoid in damage caused by Pq, in an experimental animal model, in vitro, a reduction in the level of hepatic lipoperoxidation was observed, suggesting a greater sensitivity of this tissue than the renal. Also, when in association, $\mathrm{Pq}+\mathrm{Q}$ were able to provoke inhibition of the enzyme $\delta$-aminolevulinate dehydratase ( $\delta$-ALA-D), possibly by chelation mechanism, unrelated to the sulfhydryl groups of the enzyme. In silico, Q presented good intestinal absorption, high plasma protein binding, mutagenic, carcinogenic and inhibitory potential on metabolic enzymes. Thus, it is believed that the diet rich in $Q$ or its supplementation can bring health benefits to the population, especially those exposed to herbicides, such as Pq.
\end{abstract}

Keywords: oxidative stress; in silico; pesticides antioxidant.

Resumen: Las intoxicaciones por paraquat $(\mathrm{Pq})$ son frecuentes en el país y su mecanismo de acción tóxica involucra la generación de estrés oxidativo, que puede ser combatida con antioxidantes exógenos como la quercetina ( $Q$ ). Así, al evaluar el papel de ese flavonoide en daño causado por Pq, en un modelo experimental animal, in vitro, se observó una reducción en el nivel de lipoperoxidación hepática, sugiriendo mayor sensibilidad de ese tejido que el renal. También, cuando en asociación, $\mathrm{Pq}+\mathrm{Q}$ fueron capaces de provocar la inhibición de la enzima $\delta$-aminolevulinato deshidratasa ( $\delta$-ALA-D), posiblemente por mecanismo de quelación, no relacionado a los grupos sulfhidrilos de la enzima. In silico, la Q presentó una buena absorción intestinal, alta tasa de unión de las proteínas plasmáticas, potencial mutagénico, carcinogénico e inhibitorio sobre enzimas del metabolismo. Así, se cree que la dieta alimentaria rica en $Q$ o su suplementación pueden traer beneficios a la salud de la población, especialmente aquellos expuestos a los herbicidas, como el Pq.

Palabras clave: estrés oxidativo; In silico; los pesticidas; antioxidante. 


\section{INTRODUÇÃO}

O Paraquat (Pq) (1,1'-dimetil-4,4'-bipiridilo dicloreto) é um herbicida encontrado no comércio internacional há muito tempo, sendo comercializado desde 1962. No mercado nacional, o produto é comercializado como

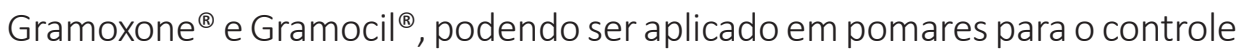
de gramíneas. Além disso, o herbicida tem aplicação nas culturas de milho, cana-de-açúcar e soja, combatendo ervas daninhas como o Bidens pilosa (picão-preto) e Lolium multiflorum (azevém), em culturas perenes, tais como palmeira (coco), uva, abacate, café, citro, cacau, maçã, pêssego, seringueira e banana, e na dessecação de culturas de milho, arroz, sorgo, algodão e batata.

No Brasil, vários casos de intoxicações por agrotóxicos são relatados todos os anos, além das ocorrências que não são diagnosticadas pela falta de conhecimentos clínico-toxicológicos dos profissionais da saúde. Um dos exemplos dos praguicidas potencialmente tóxicos é o Pq. Há um alto índice de mortes provocadas por este composto, justificado pela falta de um antídoto eficaz que reverta o quadro clínico do paciente, o que demonstra a importância da pesquisa de substâncias que possam prevenir ou tratar estes casos.

O composto já mostrou ser tóxico para os pulmões, fígados e rins, em humanos e gado, quando inalado ou ingerido por via oral (acidental ou intencional). Seu mecanismo de toxicidade está relacionado com a formação de radicais livres e espécies reativas de oxigênio (EROs), como o peróxido de hidrogênio $\left(\mathrm{H}_{2} \mathrm{O}_{2}\right)$, radical superóxido $\left(\mathrm{O}_{2} \bullet-\right)$ e radical hidroxila $(\mathrm{OH} \bullet)$, que reagem com ácidos graxos lesionando o DNA, proteínas e membranas celulares, gerando uma situação de estresse oxidativo.

Para combater as EROs, o organismo apresenta dois tipos de sistemas antioxidantes, o sistema enzimático e o sistema não enzimático. 0 enzimático é composto principalmente pela superóxido dismutase (SOD), a catalase (CAT), a glutationa redutase (GR) e a glutationa peroxidase (GPX). O sistema não enzimático é composto por substâncias como o $\beta$-caroteno (provitamina A), a alfa tocoferol (vitamina E), o ácido ascórbico (vitamina C), a glutationa (GSH), os fenóis e flavonoides, entre outras, sendo que a suplementação dietética com tais antioxidantes exógenos pode apresentar ações benéficas ao organismo. 
Entre os flavonoides, a Quercetina (3,5,7,3'-4'-pentahidroxiflavona) provém da ingestão cotidiana na dieta humana. Esta substância tem importante atividade antioxidante, secretora, quelante, cardioprotetora e bacteriostática. Algumas de suas fontes são a cebola, a maçã e o brócolis. Diversos estudos já demonstraram os efeitos benéficos do uso desta substância em situações de estresse oxidativo, entretanto muito do seu potencial permanece inexplorado. Nesse sentido, tal composto natural poderia ser usado como agente preventivo e/ou curativo em casos de intoxicação por Pq.

Entre os biomarcadores de dano oxidativo, estão as substâncias que reagem ao ácido tiobarbitúrico (TBARS), cuja medida é relacionada com o nível de peroxidação lipídica. Vários estudos já utilizaram este marcador em situações de estresse oxidativo, inclusive em modelos experimentais de dano ao Pq.

Ainda, outras moléculas biológicas podem estar relacionadas a situações de estresse oxidativo. A $\delta$-aminolevulinato desidratase ( $\delta$-ALA-D) é uma enzima com distribuição generalizada na natureza, utilizada como marcador de intoxicação por metais que competem com zinco pelo seu sítio de ligação ou que têm afinidade com grupos tióis. É um indicador indireto desta condição, além de estar vinculada a alguns tipos de doenças relacionadas com a formação do grupo heme da hemoglobina. Estudos prévios também demonstraram sua aplicação como indicador biológico de exposição crônica a praguicidas, incluindo o $\mathrm{Pq}$, quando sua atividade se apresenta inibida.

Assim, considerando a importância dos casos de intoxicação por $\mathrm{Pq}$, este estudo tem como objetivo demonstrar o potencial protetor da quercetina contra os efeitos causados pelo herbicida, através de ensaios in vitro, e avaliar, in silico, a molécula de quercetina quanto à toxicidade e às propriedades farmacocinéticas.

\section{METODOLOGIA}

\subsection{Aspectos éticos e animais experimentais}

O projeto de pesquisa foi aprovado pelo Comitê de Ética no Uso de Animais (CEUA) da Universidade de Cruz Alta (UNICRUZ), sob protocolo $003 / 16$. Os animais foram mantidos e manipulados de acordo com a 
Sociedade Brasileira de Ciência em Animais de Laboratório (SBCAL) e com a Lei $n$ o 11.794 , de 8 de outubro de 2008. Os animais utilizados foram ratos (Rattus norvegicus) machos adultos, pesando cerca de $200 \mathrm{~g} \pm 50 \mathrm{~g}$, provenientes do biotério da UNICRUZ e mantidos a $22 \pm 2{ }^{\circ} \mathrm{C}$, com $12 \mathrm{~h}$ de ciclo claro e escuro, com água e alimento ad libitum. Todos os esforços foram feitos para minimizar o número de animais utilizados, bem como seu sofrimento.

\subsection{Preparo dos tecidos e indução de dano por paraquat}

Os ratos foram eutanasiados por deslocamento cervical após anestesia inalatória, e o fígado e rim rapidamente dissecados, pesados e colocados em gelo. Os tecidos foram então homogeneizados em Tris- $\mathrm{HCl}, 10 \mathrm{mM}, \mathrm{pH}$ $7,4(1 / 10 \mathrm{p} / \mathrm{v})$ e posteriormente centrifugados a $4.000 \mathrm{rpm}$ a $4^{\circ} \mathrm{C}$ por 10 minutos (BONFANTI et al., 2011).

O sobrenadante gerado foi submetido a uma pré-incubação com quercetina $(\mathrm{Q}, \mathrm{n}=7 ; 80 \mu \mathrm{M}$,) por $30 \mathrm{~min}$ (SADOWSKA-WODA et al., 2010). Depois, uma dose de $\mathrm{Pq}$ de $1 \mathrm{mM}$ foi adicionada aos tecidos, seguindo-se uma incubação de 2 horas adicionais (WANG et al., 2014). Um grupo sem tipo de tratamento algum foi considerado o grupo controle $(C, n=7)$. Também foram feitos os grupos controle paraquat $(\mathrm{Pq}, \mathrm{n}=7)$ e controle quercetina $(\mathrm{Q}, \mathrm{n}=7)$ (Tabela 1).

Ao final do tempo de incubação, as amostras foram utilizadas para medida dos biomarcadores de estresse oxidativo. Além disso, o teor de proteína foi medido pelo método de Peterson (1977).

Tabela 1- Esquema do tratamento experimental

\begin{tabular}{lccc}
\hline Grupo & Pré-incubação (30 $\mathbf{m i n}$ ) & Tratamento $\mathbf{2 h}$ & Marcadores bioquímicos \\
\hline $\mathrm{C}$ & --- & ---- & \\
$\mathrm{Q}$ & $80 \mu \mathrm{M} \mathrm{Q}$ & --- & TBARS, NPSH e \\
$\mathrm{Pq}$ & --- & $1 \mathrm{mM} \mathrm{Pq}$ & $\delta$-ALA-D* \\
$\mathrm{Pq}+\mathrm{Q}$ & $80 \mu \mathrm{M} \mathrm{Q}$ & $1 \mathrm{mM} \mathrm{Pq}$ & \\
\hline
\end{tabular}

Fonte: os autores.

Legenda: Esquema de tratamento experimental. *A determinação da atividade da enzima $\delta$-ALA-D foi realizada apenas em tecido hepático. 


\subsection{Análise de biomarcadores de estresse oxidativo}

O nível de lipoperoxidação dos tecidos hepático e renal foi determinado através da medida das Substâncias Reativas ao Ácido Tiobarbitúrico (TBARS) e comparado à curva de calibração com malondialdeído (MDA). O MDA e demais hidroperóxidos formados no processo, quando aquecidos na presença de ácido tiobarbitúrico, formam um composto rosado que foi medido espectrofotometricamente em $532 \mathrm{~nm}$. Os resultados foram expressos por nmol MDA/mg proteína (BUEGE; AUST, 1978).

A determinação de grupamentos tiólicos não proteicos (NPSH) em tecidos hepático e renal foi realizada com a utilização do reagente de cor ácido 5',5'-ditio-bis- (2- nitrobenzoico) (DTNB); para a colorimetria e a leitura, foi realizada em espectrofotômetro em $412 \mathrm{~nm}$. Os dados foram expressos por $\mu \mathrm{mol}$ GSH/ mg proteína, baseados em uma curva de calibração com glutationa (GSH) (BOYNE; ELLMAN, 1972).

$A$ atividade da enzima $\delta$-aminolevulinato desidratase ( $\delta$-ALA-D) em tecidos hepáticos (SASSA, 1982) foi determinada através da sua reação enzimática com o substrato ácido $\delta$-aminolevulínico e formação de porfobilinogênio (PGB), o qual é medido espectrofotometricamente em $555 \mathrm{~nm}$. Os resultados foram então expressos em nmol PGB/mg proteína/h. Para investigar o possível envolvimento dos grupamentos sulfidrílicos da enzima no efeito do Pq e quercetina, um agente protetor tiólico (ditiotritol, DTT, $2 \mathrm{mM}$ ) foi utilizado, assim, a atividade da enzima também foi realizada na presença de DTT. Tal efeito foi avaliado através do índice de reativação (IR), calculado pela fórmula: $A-B / A * 100$ (1), em que A = absorbância com DTT e $B=$ absorbância sem DTT.

\subsection{Avaliação in silico}

O estudo in silico foi realizado empregando-se web servidores, de uso livre e gratuito, para predição de propriedades farmacocinéticas e toxicológicas: PreADMET, admetSAR e Lazar Toxicity Predictions. Após a construção da estrutura química da quercetina nos respectivos softwares, solicitou-se a predição de suas características. 
O PreADMEt (https://preadmet.bmdrc.kr/) fornece as propriedades druglikeness (regra dos cinco), farmacocinéticas/ADME (solubilidade, coeficiente de partição, permeabilidade em diferentes tecidos, absorção intestinal humana, ligação às proteínas plasmáticas, interação com a glicoproteína $\mathrm{P}$, interação com diferentes isoformas de citocromo P450) e toxicológicos (carcinogenicidade, mutagenicidade). O admetSAR (http://Immd.ecust.edu. cn:8000/) realiza a predição de parâmetros farmacocinéticos e toxicológicos com modelos de QSAR por regressão ou por classificação. Assim, fornece as propriedades farmacocinéticas/ADME (solubilidade, permeabilidade em diferentes tecidos, interação com a glicoproteína P, interação com diferentes isoformas de citocromo P450) e toxicológicas (toxicidade aguda, genética e reprodutiva). Já o Lazar Toxicity Predictions (https://lazar.insilico.ch/predict) permite realizar a predição da toxicidade aguda, mutagenicidade, carcinogenicidade e dose diária máxima recomendada.

Após o estudo da molécula de quercetina com tais ferramentas computacionais, os dados foram agrupados em tabela e analisados qualitativamente, de forma a sistematizar as propriedades farmacocinéticas e toxicológicas preditas.

\subsection{Análise estatística}

Os resultados obtidos foram expressos por média \pm EPM (erro padrão da média). As diferenças foram avaliadas utilizando ANOVA de uma via seguida do pós-teste Newman-Keuls de comparações múltiplas, com o software GraphPad Prism 5.01. Os valores com $p \leq 0,05$ foram considerados significativamente diferentes.

\section{RESULTADOS E DISCUSSÃO}

Como já se sabe, o mecanismo de dano do Pq ocorre pela formação de radicais livres e espécies reativas de oxigênio, demonstrando a importância da ação de antioxidantes na proteção do organismo em casos de intoxicação. A avaliação de biomarcadores relacionados ao estresse oxidativo, tais como TBARS, níveis de NPSH e atividade da enzima $\delta$-ALA-D, é de extrema 
importância para a determinação das características protetoras do flavonoide em estudo (ALMEIDA et al., 2016; DE LUCCA et al., 2016; KOROVILA et al., 2017; ANTUNES NETO et al., 2008).

A lipoperoxidação ocorre quando os radicais livres formados durante o processo de estresse oxidativo reagem com os ácidos graxos das membranas celulares alterando sua permeabilidade. Através da medida das substâncias reativas do ácido tiobarbitúrico, é possível avaliar o nível de peroxidação lipídica celular (SILVA; FERRARI, 2011).

No presente estudo, o Pq causou aumento no nível de TBARS quando comparado com o grupo controle, em tecido hepático (Figura 1). A pré-incubação do tecido com quercetina evitou o aumento dos níveis de lipoperoxidação, sugerindo sua ação protetora nesse tecido. Esse resultado é interessante, considerando que as intoxicações agudas fulminantes por Pq causam insuficiência hepatocelular, entre outras alterações, sugerindo uma possível aplicabilidade clínica para o flavonoide em estudo (ALMEIDA et al., 2016; SCHMITT et al., 2006).

Entretanto não foi observado dano causado pelo $\mathrm{Pq}$ em tecido renal, sugerindo que o modelo experimental utilizado demonstrou ser mais sensível para tecido hepático. De fato, em outro estudo já realizado, foi demonstrado que o Pq causa dano renal, porém a exposição ao herbicida foi realizada in vivo, na dose de $60 \mathrm{mg} / \mathrm{kg}$ pela via intraperitoneal (YOON et al., 2011). Apesar disso, é possível observar um efeito protetor da quercetina em isolado ou em associação ao Pq, pois esta reduziu o nível de lipoperoxidação com relação ao grupo controle e grupo Pq também no tecido renal. 
Figura 1- Níveis de lipoperoxidação

RIM

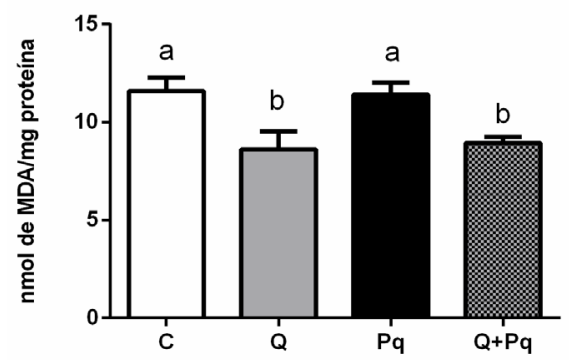

FÍGADO

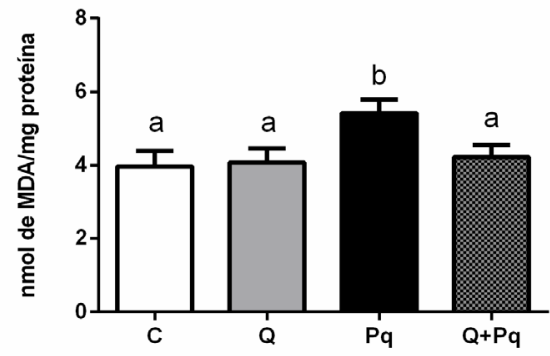

Fonte: Elaborada pelos autores.

Legenda: Os dados estão expressos em média \pm EPM e foram analisados por ANOVA de uma via seguida de pós-teste de Newman-Keuls. Letras diferentes indicam diferenças estatisticamente significativas entre os grupos $(n=7)$, assumindo um $p \leq 0,05 . C=$ grupo controle; $\mathrm{Q}=$ grupo quercetina; $\mathrm{Pq}=$ grupo controle paraquat; $\mathrm{Q}+\mathrm{Pq}=$ grupo quercetina + paraquat.

A glutationa (GSH) é o principal antioxidante endógeno encontrado no nosso organismo. Algumas organelas celulares têm sua própria reserva desta substância como mecanismo de defesa contra o estresse oxidativo. Sendo assim, é um importante indicador do estado redox celular, que pode ser determinado pela quantificação inespecífica de grupamentos tiólicos não proteicos (GABRIEL, 2018; KOROVILA et al., 2017).

Quanto aos níveis de NPSH (Figura 2), o Pq não foi capaz de consumir esse antioxidante na dose utilizada, assim como não foi possível verificar o efeito protetor da quercetina nos tecidos hepático e renal.

Entretanto estudos anteriores do nosso grupo de pesquisa já demonstraram que o Pq diminui os níveis de NPSH em cérebro de ratos, in vitro, nas mesmas condições experimentais. Isso se deve às diferentes quantidades de glutationa disponíveis em diferentes tecidos do organismo. O cérebro apresenta uma capacidade antioxidante deficiente, podendo estar mais susceptível às alterações oxidativas do que os tecidos hepático e renal (OLIVEIRA et al., 2018). Outros estudos também demonstram que, em outros tecidos, como o cerebral e o pulmonar, ocorre uma diminuição significativa da glutationa e também aumento da lipoperoxidação após a exposição ao Pq (DJUKIC et al., 2012; KANG et al., 2010; PARK., 2010). 
Figura 2- Níveis de grupamentos tiólicos não proteicos (NPSH)

RIM

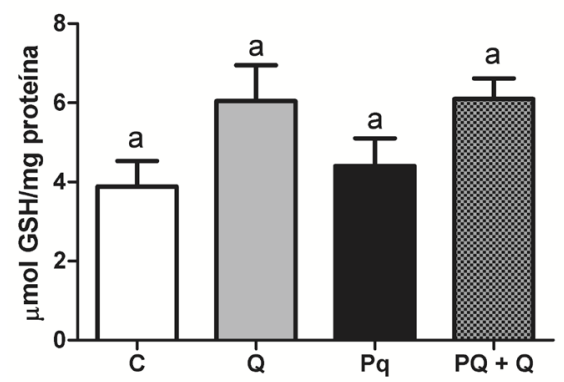

FÍGADO

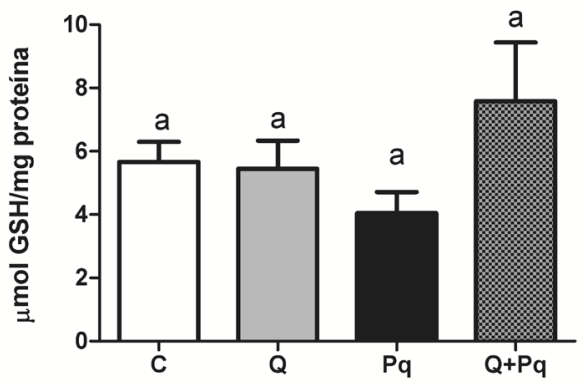

Fonte: Elaborada pelos autores.

Legenda: Os dados estão expressos em média \pm EPM e foram analisados por ANOVA de uma via seguida de pós-teste de Newman-Keuls. Letras diferentes indicam diferenças estatisticamente significativas entre os grupos $(n=7)$, assumindo um $p \leq 0,05 . C=$ grupo controle; $\mathrm{Q}=$ grupo quercetina; $\mathrm{Pq}=$ grupo controle paraquat; $\mathrm{Q}+\mathrm{Pq}=$ grupo quercetina + paraquat.

A atividade da enzima $\delta$ - ALA-D pode ser dosada e utilizada como marcador indireto em situações de estresse oxidativo, sendo inibida por ter em sua estrutura grupamentos sulfidrila, os quais são sensíveis aos agentes oxidantes (DE LUCCA et al., 2016).

Nossos resultados demostraram que, apenas quando o $\mathrm{Pq}$ foi incubado juntamente da quercetina (Grupo Q + Pq), houve redução da atividade enzimática da $\delta$-ALA-D (Tabela 2). Quando as duas substâncias foram incubadas separadamente, não ocorreu nenhum tipo de inibição enzimática.

Um dos mecanismos que podem ser propostos para explicar este acontecimento é uma possível intensificação do ciclo redox do Pq através da ação da quercetina. Outra provável explicação é que, além de grupamentos sulfidrílicos, a enzima também precisa de zinco para exercer sua atividade normal, sendo inibida por substâncias que causem indisponibilidade deste ín (ABDALLA et al., 2014; GAMBINI et al., 2012; SAVEGNAGO et al., 2013). Sendo a quercetina e o Pq dois agentes quelantes, esses podem ter causado tal indisponibilidade quando utilizados em conjunto (MIRANDA; MELO; ARAÚJO, 2017; VETROVA et al., 2017). Entretanto esse resultado não invalida os efeitos protetores demonstrados, já que não se observou indução de lipoperoxidação ou diminuição de NPSH. 
Tabela 2- Efeito da quercetina e paraquat sobre a atividade da enzima $\delta$-ALA-D

\begin{tabular}{lcccc}
\hline & Controle & $\mathbf{Q}$ & $\mathbf{P q}$ & $\mathbf{Q}+\mathbf{P q}$ \\
\hline ALA-D & $2,14 \pm 0,26^{\mathrm{a}}$ & $1,99 \pm 0,28^{\mathrm{a}}$ & $2,05 \pm 0,22^{\mathrm{a}}$ & $1,11 \pm 0,11^{\mathrm{b}}$ \\
ALA-D DTT $^{\mathrm{a}}$ & $5,12 \pm 0,31^{\mathrm{a}}$ & $3,01 \pm 0,37^{\mathrm{b}}$ & $5,17 \pm 0,35^{\mathrm{a}, \mathrm{c}}$ & $1,63 \pm 0,18^{\mathrm{d}}$ \\
IR (\%) & $58,55 \pm 3,42^{\mathrm{a}}$ & $34,96 \pm 1,93^{\mathrm{b}}$ & $60,34 \pm 2,57^{\mathrm{a}, \mathrm{c}}$ & $27,29 \pm 7,11^{\mathrm{b}, \mathrm{d}}$ \\
\hline
\end{tabular}

Fonte: Elaborada pelos autores.

Legenda: Atividade da enzima $\delta$-ALA-D, em nmol PGB/mg proteína/h. Os dados foram expressos em média \pm EPM e foram analisados por ANOVA de uma via seguida de pós-teste de Newman-Keuls. Letras diferentes na mesma linha da tabela, indicam diferenças estatisticamente significativas entre os grupos $(n=6)$, assumindo um $p \leq 0,05 . C=$ grupo controle; $\mathrm{Q}=$ grupo quercetina; $\mathrm{Pq}=$ grupo controle paraquat; $\mathrm{Q}+\mathrm{Pq}=$ grupo quercetina + paraquat, $I R=$ índice de reativação.

De fato, aparentemente, a inibição enzimática não foi causada por oxidação dos grupamentos sulfidrílicos presentes na enzima, já que o índice de reativação (IR) não se mostrou aumentado nesses grupos. Além disso, os resultados obtidos sobre avaliação da atividade da enzima $\delta$-ALA-D (Tabela 2) condizem com os resultados encontrados na avaliação dos níveis de NPSH (Figura 2), sugerindo que o Pq não atua sobre os grupamentos sulfidrílicos, sejam eles isolados ou enzimáticos. Isso demonstra que podem haver outros mecanismos de inibição que merecem ser estudados.

Além de toda esta avaliação biológica, é importante conhecer as propriedades farmacocinéticas e toxicológicas da quercetina. Para isso, foram realizadas predições in silico (Tabela 3 ) que demonstraram que a quercetina apresenta viabilidade de absorção intestinal, mas não dérmica, sugerindo possibilidade de administração pela via oral. Também, apresentou alta taxa de ligação às proteínas plasmáticas, o que pode levar à menor disponibilidade do flavonoide no local de ação.

Quanto ao efeito sobre o metabolismo, a quercetina apresentou possibilidade de inibição das enzimas CYP450, CYP2C19, CYP2C9, CYP3A4 e CYP1A2, sugerindo um potencial de interação medicamentosa, já que pode ocasionar diminuição do metabolismo de fármacos metabolizados por essas isoformas do citocromo P450. Além disso, mostrou-se não inibidora da glicoproteína P, proteína transportadora envolvida no efluxo de fármacos e xenobióticos (GOODMAN; GILMAN, 2012). 
Quanto à penetração na barreira hematoencefálica (BHE), uma das ferramentas utilizadas indicou a possibilidade de penetração, enquanto outra indicou baixos índices. Isso se deve ao fato de que as pesquisas são feitas através da análise de bancos de dados, podendo apresentar inconsistências. Entretanto alguns autores já estudaram os mecanismos de transporte através da BHE dos flavonoides e demonstraram que a quercetina pode ser captada por culturas celulares simulando a $\mathrm{BHE}$, in vitro, e encontrada em todas as regiões cerebrais analisadas após perfusão in situ, permitindo a conclusão de que é capaz de ultrapassar a BHE (DOVICHI; LAJOLO, 2011).

Com relação à toxicidade, os modelos in silico sugeriram que a quercetina possivelmente seja carcinogênica em ratos, mas não em camundongos, além de mutagênica. Sua toxicidade aguda foi considerada baixa, porém alguns estudos já demonstraram que, em doses superiores a $500 \mathrm{mg} / \mathrm{kg}$ de peso corporal (ratos), podem ser formados compostos mutagênicos que são excretados nas fezes e urina; também, em longos períodos de administração, ocorrem lesões neoplásicas renais (ALVES et al., 2010). 
Tabela 3- Estudo in silico em diferentes softwares

\begin{tabular}{|c|c|c|}
\hline Software & Parâmetros avaliados & Quercetina \\
\hline \multirow{5}{*}{$\begin{array}{c}\text { Lazar Toxicity } \\
\text { Predictions }\end{array}$} & Penetração na BHE & Penetrante \\
\hline & Carcinogenicidade (roedores) & Não \\
\hline & Carcinogenicidade (rato) & Não \\
\hline & Carcinogenicidade (camundongo) & Não \\
\hline & Mutagenicidade (Salmonella typhimurium) & Mutagênico \\
\hline \multirow[t]{15}{*}{ PreADMET } & Penetração na BHE & 0.172765 \\
\hline & CYP2C19 - Inibição & Inibição \\
\hline & CYP2C9 - Inibição & Inibição \\
\hline & CYP2D6 - Inibição & Não \\
\hline & CYP2D6 - Substrato & Não \\
\hline & CYP3A4 - Substrato & Inibição \\
\hline & CYP3A4 - Substrato & Não \\
\hline & Absorção intestinal humana (\%) & 63.485215 \\
\hline & Glicoproteina-P - Inibição & Não \\
\hline & Ligação às proteínas plasmáticas (\%) & 93.236103 \\
\hline & Permeabilidade na pele $(\mathrm{cm} / \mathrm{h})$ & -4.43341 \\
\hline & Toxicidade aguda (algas) & 0.037813 \\
\hline & Ames Test & Mutagênico \\
\hline & Carcinogenicidade (camundongo) & Negativo \\
\hline & Carcinogenicidade (ratos) & Positivo \\
\hline \multirow[t]{12}{*}{ AdmetSAR } & Penetração na BHE & Negativo \\
\hline & Absorção intestinal humana & Positivo \\
\hline & Glicoproteína-P & Não inibidor \\
\hline & CYP450 2C9 - Substrato & Não \\
\hline & CYP450 2D6 - Substrato & Não \\
\hline & CYP450 3A4 - Substrato & Não \\
\hline & CYP450 1A2 - Inibidor & Sim \\
\hline & CYP450 2C9 - Inibidor & Não \\
\hline & CYP450 2D6 - Inibidor & Não \\
\hline & CYP450 2C19 - Inibidor & Não \\
\hline & CYP450 2C19 - Inibidor & Sim \\
\hline & Carcinogenicidade & Não \\
\hline
\end{tabular}

Fonte: Os autores. 


\section{CONCLUSÃO}

Pode-se concluir que a quercetina protege o tecido hepático do dano causado por Pq, ao diminuir os níveis de lipoperoxidação. Ainda, os lipídios podem ter maior sensibilidade aos danos do herbicida quando comparados com os grupamentos sulfidrílicos, que não sofreram nenhuma alteração significativa. Além disso, a atividade da $\delta$-ALA-D não demonstrou ser um bom marcador de lesão causada pelo $\mathrm{Pq}$, pois não refletiu o dano causado pelo agrotóxico em questão.

Quanto à avaliação in silico da quercetina, seu potencial mutagênico, de interação com as CYPs e possibilidade de penetração na BHE, alerta para a necessidade de maiores estudos relacionados à toxicocinética de produtos farmacêuticos contendo quercetina.

Apesar disso, acredita-se que a dieta alimentar rica em quercetina ou sua suplementação podem trazer benefícios à saúde da população, especialmente àqueles expostos a herbicidas, como o paraquat.

\section{REFERÊNCIAS}

ABDALLA, F. H. et al. Quercetin protects the impairment of memory and anxiogenic-like behavior in rats exposed to cadmium: possible involvement of the acetylcholinesterase and $\mathrm{Na}+, \mathrm{K}+-$ ATPase activities. Physiology \& Behavior, v. 135, p. 152-67, 2014.

ALMEIDA, L. L. et al. Efeito protetor da melatonina sobre intoxicações por herbicidas. Pesquisa Veterinária Brasileira, Rio de Janeiro, v. 36, n. 3, p. 174-80, mar. 2016.

ALVES, A. M. P. et al. Aspectos gerais e abordagem terapêutica da quercetina sobre as complicações do diabetes causadas pelo estresse oxidativo. Arquivos de Ciências da Saúde da UNIPAR, Umuarama, PR, v. 14, n. 2, p. 179-86, maio/ago. 2010.

ANTUNES NETO, A. et al. Níveis comparativos de estresse oxidativo em camundongos em duas situações do limite orgânico: overreaching induzido por treinamento de natação e câncer. Revista Brasileira de Medicina do Esporte, São Paulo, v. 14, n. 6, p. 548-52, nov./dez. 2008.

BONFANTI, G. et al. $\delta$-Aminolevulinate dehydratase activity in type 2 diabetic patients and its association with lipid profile and oxidative stress. Clinical Biochemistry, v. 44, n. 13, p. 1105-9, 2011. 
BOYNE, A. F.; ELLMAN, G. L. A methodology for analysis of tissue sulfhydryl components. Analytical Biochemistry, v. 46, p. 639-53, 1972.

BUEGE, J. A.; AUST, S. D. Microsomal lipid peroxidation. Methods in Enzymology, V. 52, p. 302-10, 1978.

DE LUCCA, L. et al. Delta-aminolevulinate dehydratase activity and oxidative stress markers in preeclampsia. Biomedicine \& Pharmacotherapy, v. 84, p. 224-9, 2016.

DJUKIC, M. M. et al. Protective role of glutathione reductase in paraquat induced neurotoxicity. Chemico-Biological Interactions, v. 199, n. 2, p. 74-86, ago. 2012.

DOVICHI, S.; LAJOLO, F. M. Flavonoides e sua relação com doenças do Sistema Nervoso Central. Nutrire, São Paulo, v. 36, n. 2, p. 123-35, 2011.

GABRIEL, E. A. Uso de antioxidantes na cirurgia cardiovascular. International Journal of Nutrology, v. 11, n. S 01, p. Trab781, 2018.

GAMBINI, I. C. et al. Atividade da enzima ácido $\delta$-aminolevulínico desidratase em viticultores expostos a agrotóxicos. In: FÓRUM DE EXTENSÃO E CULTURA DA UEM: A EXTENSÃO UNIVERSITÁRIA E O DESENVOLVIMENTO REGIONAL, 10., 2012, Maringá, PR. Anais [...]. Maringá, PR: UEM, 2012.

GOODMAN, L. S.; GILMAN, A. As bases farmacológicas da terapêutica. 12. ed. Rio de Janeiro: McGraw-Hill, 2012.

KANG, M. J. et al. Selective vulnerability of the striatal subregions of C57BL/6 mice to paraquat. Toxicology Letters, v. 195, n. 2-3, p. 127-34, 2010.

KOROVILA, I. et al. Proteostasis, oxidative stress and aging. Redox Biology, v. 13, p. 550-67, 2017.

MIRANDA, A. A. C.; MELO, L. F.; ARAÚJO, A. E. Impactos dos agrotóxicos na saúde do solo e humana: uma revisão. In: CONGRESSO INTERNACIONAL DAS CIÊNCIAS AGRÁRIAS COINTER - PDVAGRO, 2., 2017, Natal. Disponível em: https://cointer-pdvagro.com.br/wp-content/uploads/2018/02/IMPACTOSDOS-AGROT\%C3\%93XICOS-NA-SA\%C3\%9ADE-DO-SOLO-E-HUMANA-UMAREVIS\%C3\%830.pdf. Acesso em: 1ํ nov. 2018.

OLIVEIRA, A. F. et al. Avaliação do efeito antioxidante do extrato hidroetanólico de luehea divaricata mart. Em um modelo de oxidação induzido por paraquat em 
cérebro de ratos. In: TORRES, V. L. G. (Org.). Princípios e Fundamentos das Ciências da Saúde 3. 1. ed. Ponta Grossa, PR: Atena, 2018. v. 3, p. 27-37.

PARK, H. K. et al. Protective effect of quercetin against paraquat-induced lung injury in rats. Life Sciences, v. 87, n. 5-6, p. 181-6, 2010.

PETERSON, G. L. A simplification of the protein assay method of Lowry et al., which is more generally applicable. Anal Biochemistry, v. 83, n. 2, p. 346-56, 1977.

SADOWSKA-WODA, l. et al. Effect of selected antioxidants in b-cyfluthrin-induced oxidative stress in human erythrocytes in vitro. Toxicology in Vitro, v. 24, n. 3, p. 879-84, 2010.

SASSA, S. Delta-aminolevulinic acid dehydratase assay. Enzyme, v. 28, p. 133-45, 1982.

SAVEGNAGO, L. et al. Synthesis and antioxidant properties of novel quinolinechalcogenium compounds. Tetrahedron Letters, v. 54, n. 1, p. 40-4, 2013.

SCHMITT, G. C. et al. Aspectos gerais e diagnóstico clinicolaboratorial da intoxicação por paraquat. Jornal Brasileiro de Patologia e Medicina Laboratorial, Rio de Janeiro, v. 42, n. 4, p. 235-43, ago. 2006.

SILVA, W. J. M.; FERRARI, C. K. B. Metabolismo mitocondrial, radicais livres e envelhecimento. Revista Brasileira de Geriatria e Gerontologia, Rio de Janeiro, v. 14, n. 3, p. 441-51, 2011.

VETROVA, E. V. et al. A simple way for the preparation of natural antioxidant quercetin from rutin by subcritical water. Journal of Natural Science, Biology and Medicine, v. 8, n. 2, p. 213-5, 2017.

WANG, F. et al. Mechanical stretch exacerbates the cell death in SH-SY5Y cells exposed to paraquat: mitochondrial dysfunction and oxidative stress. Neurotoxicology, v. 41, p. 54-63, 2014.

YOON, S. P. et al. Protective effects of chitosan oligosaccharide on paraquat-induced nephrotoxicity in rats. Food and Chemical Toxicology, v. 49, n. 8, p. 1828-33, 2011. 